\title{
Empirical Study on the Urbanization Promoting the Chinese Economic Growth
}

\author{
Jing Huirong \\ School of Management, Yunnan University of Nationalities, Kunming, Yunnan, P.R.China \\ 1307608193@qq.com; goughuirong@aliyun.com
}

Keywords: urbanization, economic growth, empirical research

\begin{abstract}
This paper select the section data of China's 31 provinces, autonomous regions and municipalities directly under the Central Government in the year of 2011, use the Eviews6.0 metrology software, set up the production function model, and change it into the econometric model to empirical test theoretical model of the urbanization development to promote economic growth and its related the theoretical conclusions. At significant level of $1 \%$, the regression parameters of the urbanization development and capital and labor are all significant not 0 , and at the significance level $1 \%$, the urbanization rate increasing 1 percentage, the output GDP increasing 0.66 percent, while the output elasticity of capital and labor are 0.71 and 0.37 respectively.
\end{abstract}

\section{Introduction}

In the 21st century, China is one of the fastest growing countries in the world economy, China's urbanization development becomes the focus of people attention too, because the urbanization development of China and China's economic growth is basically synchronized.

\section{The related theoretical explanation of the China's urban-rural dual economic structure}

The best theory to explain the present situation of China's urban and rural economic structure is a dual economic structure theory of Lewis and other researchers. The literature [1] built a theoretical model of dual economic structure, researched the economic development from the perspective of industrial and agricultural sector's labor demand and supply, and form its equilibrium.

The literature [1] believed that there were two mutually independent but interlinked sectors economy in the early industrialization and less developed countries, the one was the modern urban industrial sector which was a market-oriented and advanced technology economic, the other was a traditional agricultural sector which was a huge backward and self-sufficiency economy. The traditional sectors owned a large excess of labor and existence of the hidden unemployment, the traditional sectors can provide a steady stream of labor supply for the expansion of the modern sector. Due to the existence of the traditional sectors overflow labor supply, labor-intensive and capital savings industries would be rapid expansion because of low cost, further ,Bring about economic growth.

In the 1960s Lewis's theory has been developed, The literature [2] noted that the role of agricultural surplus, and built the literature [1] model based on the literature [1] dual economic model. Because born out of the model of the literature [1], Descendants call it as the Lewis-Ranis-Fei model. Their main point is: the traditional sector of agriculture development relies on the output of surplus labor, the industrial sector acts as the power source of its own sustainable development and absorbing surplus labor, it promotes economic development which lies in the combination of surplus labor in agriculture and industrial capital. This is the original meaning of the dual economic structure.

The literature [3] Founded the model of literature [2] based on the neo-classical economics perspective. It believed that the surplus agricultural labor is a necessary condition which transfer the labor from traditional sector to the modern sector, and agricultural surplus the greater, the faster development of the modern sector, the more smoothly transfer of the labor force in agriculture. 
The research on China's economic structure has always been a hot issue of domestic theoretical discussion. Especially, that the empirical study on the urbanization promoting the Chinese economic growth has been a hot issue.

The literature [4] uses coordination theory, through co-integration model to study the relationships between urbanization and economic growth, the results showed that: the urbanization and economic growth are impacted by many factors, but there are the interactions between the urbanization and economic growth.

Literature [5] Established the error correction cointegration model about the three variables urbanization, the income gap between urban and rural areas, and economic growth. Study the relationships of cointegration, causality and the long-term changes between variables. Research shows that the income gap is lower between urban and rural areas, that the urbanization rate is large will be accompanied by weighted economic growth

Literature [6]Using the VAR model empirical analysis, analyzes the mechanism of action in Shandong province of urbanization, the economic growth and the consumption of urban residents between1995 - 2012. The results show that: the urbanization and urban - rural income gap exists between the expansion of mutual influence; the process of urbanization has a great effect on economic growth; economic growth has had a positive effect on the expansion of the urban - rural income gap. That the long - term and the expansion of income gap between urban and rural areas has restricted function on economic growth..

Literature [7]contructs a regional economic growth model under the action of regional spillovers to analyze the dynamic mechanism between the regional spillovers in urbanization and the regional economic growth convergence. The study shows that the regional spillovers in urbanization and the regional economic growth convergence would supplement each other, i.e. The speed of the occurance of economic growth convergence in Chengdu-Chongqing Economic Zone is 3.16\%. Meanwhile, the contribution of human capital investment to economic growth is greater than that of material capital investment to economic growth.

In summary, the Lewis' dual economic structure theoretical model could explain the problem of China economic growth under the condition of funds shortage since China founding. However, all the studies existence do not from the production perspective give that the agricultural sector surplus labor combined with the industrial capital how to improve the economic outputs thereby contribute to economic growth.

\section{Empirical study of urbanization development promote China's economic growth}

\subsection{Research methods and data sources and processing}

The Section data of China's 31 provinces, autonomous regions and municipalities directly under the Central Government are Selected in the year of 2011, the Eviews6.0 metrology software is used, the production function model is transformed into the econometric model to empirical test theoretical model of the urbanization development promote economic growth and its related the theoretical conclusions.

The data is come from the China Statistical Yearbook 2011, the output value use the GDP of China's 31 provinces, autonomous regions and municipalities directly under the Central Government (Unit: 100 million Chinese yuan), is denoted by y. the urbanization level is used the proportion of the urban population to total population(unit: \%), is denoted by u. labors are used aggregate value of the number of employed persons according to private and individual enterprises corresponding region (unit: 0.01million), is denoted by 1 . the capitals are used the capital formation for these 31 districts (unit: 0.1billion), denoted by $\mathrm{k}$.

\subsection{Model processing and measurement}

More clearly describe the relationship between labor, capital and the development of urbanization affecting economic outputs, further increasing urbanization development element in the Cobb Douglas production function, modify the production function which contains the technical progress, 
build the production function model of urbanization development which promote economic growth, The output function is set as follows:

$$
y=A(1+\Delta u)^{\gamma} k^{\alpha} l^{\beta}
$$

$\mathrm{y}$ : The amount of the economic output

$\mathrm{A}, \alpha, \beta, \gamma$ : constants

$\mathrm{K}$ : The amount of capitals investment of the economy

L: The amount of labors input of the economy

$\Delta u$ : The growth rate of urbanization

In order to facilitate the empirical measurement, the production function of urbanization development promoting economic growth is expand in accordance to the Taylor series, at $\Delta u=0$, and take two items, then

$$
(1+\Delta u)^{\gamma}=1+\gamma \square u+\ldots+\frac{\gamma(\gamma-1) \ldots(\gamma-n+1)}{n !} \square u^{n}+\ldots \approx 1+\gamma \square u, \square u \in(0,1)
$$

Use the exponential function of $e^{x}$, make ${ }^{x=\Delta u \gamma}$ expand the $e^{\Delta u \gamma}$ in accordance to the Taylor series, at $\Delta u \gamma=0$, and take two items, then

$$
\mathrm{e}^{\square u \gamma}=1+\gamma \square u+\ldots+\frac{1}{n !}(\gamma \square u)^{n}+\ldots \approx 1+\gamma \square u, \square u \in(0,1)
$$

Thus, the production function containing the element of urbanization development is:

$$
y=A(1+\Delta u)^{\gamma} k^{\alpha} l^{\beta} \approx A e^{\Delta u \gamma} k^{\alpha} l^{\beta}, \Delta u \in(0,1)
$$

In order to facilitate the measurement of production function

$$
y \approx A e^{\Delta u \gamma} k^{\alpha} l^{\beta}, \triangle u \in(0,1)
$$

Natural logarithm on both sides of the equation (5), and econometric model is:

$$
\log y_{i}=c+\gamma \square u_{i}+\alpha \log k_{i}+\beta \log l_{i}+\varepsilon_{i}, i=1 \ldots 31
$$

In order to facilitate Eviews6.0 software identification the symbol, make

$\Delta u=u / 100$

so the above model is :

$$
\log y_{i}=c+\gamma \frac{u_{i}}{100}+\alpha \log k_{i}+\beta \log l_{i}+\varepsilon_{i}, i=1 \ldots 31
$$

Using Eviews6.0 software, using the least squares method to estimate parameters, to avoid the bias of the regression parameter variance and the corresponding statistics because of the heteroscedasticity and autocorrelation, using Newey-West heteroscedasticity autocorrelation consistent covariance corrects parameter variance. Regression measurement equation is:

$$
\begin{aligned}
& \log y=0.47+0.66 \frac{u}{100}+0.71 \log k+0.37 \log l \\
& (t \text {-statistic } \quad 2.36 \quad 5.62 \quad 15.32 \quad 9.36) \\
& R \text {-squareed } \quad 0.986 \text {, Adjusted } R \text {-squareed } 0.985 \\
& F \text {-statistic } 648.63
\end{aligned}
$$

$\mathrm{T}$ statistic corresponding parameters are given in the below equation brackets, And then the following line shows the goodness of fit coefficients and the adjustment goodness of fit coefficients and the F statistic of equations. From the above results, it can be seen that: the goodness of fit coefficients of the model and the adjusted goodness of fit coefficients are high, equation significant test statistic $\mathrm{F}=648.63$, at significant level of $1 \%$, the equation is significant established. $\mathrm{T}$ test statistic of the regression parameters can be seen, at the $1 \%$ significance level, the regression parameters of the urbanization development and capital and labor are all significant not 0 , and at $1 \%$ significance level, the urbanization rate increasing 1 percentage, the output GDP increasing 0.66 
percent, while the output elasticity of capital and output elasticity of labor are 0.71 and 0.37 respectively.

\section{Summary}

This paper select the section data of China's 31 provinces, autonomous regions and municipalities directly under the Central Government in the year of 2011, use the Eviews6.0 metrology software, set up the production function model, and change it into the econometric model to empirical test theoretical model of the urbanization development to promote economic growth and its related the theoretical conclusions. At significant level of 1\%, the regression parameters of the urbanization development and capital and labor are all significant not 0 ,and at the significance level 1\%, the urbanization rate increasing 1 percentage, the output GDP increasing 0.66 percent, while the output elasticity of capital and labor are 0.71 and 0.37 respectively.

\section{References}

[1] Lewis, WA Economic Development with Unlimited Supply of Labor. The Manchester School, 1954, VoL. 22, No. 2: $139 \sim 191$

[2] Ranis, G., \& Fei, JCH A Theory of Economic Development, The American Economic Review, 1961, Vol. 51, No. 4: $533 \sim 565$

[3] Jorgenson, DW The Development of a Dual Economy. Economic Journal, 1961, VoL. 71, No. 282: $309 \sim 334$

[4] Zhou Xiaogang, Chen dongyou, The Empirical Analysis about the Cointegration Relationships between Jiangxi urbanization and the economic growth [J]. The Science of Jiangxi 2008 (02) (in Chinese)

[5] Chen Jinsong,Liu Qiannan, Empirical studies on the relationships about the income gap between urban and rural areas, the urbanization and economic growth [J]Statistics \& Decision, 2014(17) (in Chinese)

[6] GAO Xiao - Hua, Structural Characteristics and Development Trend of Consumption of Urban Residents In Shandong Province Empirical Research[J]. Journal of Inner Mongolia University of Finance and Economics, 2014(5). (in Chinese)

[7] Shen Yun, Cao Yue-qun, Peng Xiao-bing, Regional Spillovers in Urbanization and Regional Economic Growth Convergence: Based on Empirical Envidences of Chengdu-Chongqing Economic Zone[J] Journal of Jiangxi university of finance and economics,2014(5) 